\title{
Antimicrobial activity and cytotoxicity of triterpenes isolated from leaves of Maytenus undata (Celastraceae)
}

Tsholofelo Abednego Mokoka ${ }^{1,2}$, Lyndy Joy McGaw ${ }^{1 *}$, Ladislaus Kakore Mdee ${ }^{1,3}$, Victor Patrick Bagla ${ }^{1,4}$, Ezekiel Olugbenga Iwalewa ${ }^{1,5}$ and Jacobus Nicolaas Eloff ${ }^{1}$

\begin{abstract}
Background: Plants of the genus Maytenus belong to the family Celastraceae and are widely used in folk medicine as anti-tumour, anti-asthmatic, analgesic, anti-inflammatory, antimicrobial and anti-ulcer agents, and as a treatment for stomach problems. The aim of this study was to isolate and identify active compounds with antifungal activity from Maytenus undata after a preliminary study highlighted promising activity in crude extracts.

Methods: Sequential extracts of M. undata leaves prepared using hexane, dichloromethane (DCM), acetone and methanol (MeOH) were tested for activity against Cryptococcus neoformans, a fungal organism implicated in opportunistic infections. Bioassay-guided fractionation of the hexane extract using C. neoformans as test organism was carried out to isolate antifungal compounds. The cytotoxicity of compounds isolated in sufficient quantities was evaluated using a tetrazolium-based colorimetric cellular assay (MTT) and a haemagglutination assay (HA).

Results: The hexane extract was most active with an MIC of $20 \mu \mathrm{g} / \mathrm{ml}$ against $C$. neoformans. The triterpene compounds friedelin (1), epifriedelanol (2), taraxerol (3), 3-oxo-11a-methoxyolean-12-ene-30-oic acid (4), 3-oxo-11ahydroxyolean-12-ene-30-oic acid (5) and 3,11-dihydroxyolean-12-ene-30-oic acid (6) were isolated. Compound 6 was isolated for the first time from a plant species. The antimicrobial activity of compounds 1, 3, 5 and 6 was determined against a range of bacteria and fungi implicated in opportunistic and nosocomial infections. Compounds 5 and 6 were the most active against all the tested microorganisms with MIC values ranging between 24 and $63 \mu \mathrm{g} / \mathrm{ml}$, except against Staphylococcus aureus which was relatively resistant. Compounds 1 and 3 had a low toxicity with an $\mathrm{LC}_{50}>200 \mathrm{\mu g} / \mathrm{ml}$ towards Vero cells in the MTT assay. Compounds 5 and 6 were toxic with $L C_{50}$ values of $6.03 \pm 0.02$ and $2.98 \pm 0.01 \mu \mathrm{g} / \mathrm{ml}$, respectively. Compounds 1 and 3 similarly were not toxic to the red blood cells (RBCs) but compounds 5 and 6 were toxic, showing HA titer values of 1.33 and 0.67 respectively.

Conclusions: Compounds 5 and 6 were the most active but were also relatively cytotoxic to monkey kidney cells and red blood cells, while the other isolated compounds were less active and less cytotoxic.
\end{abstract}

Keywords: Maytenus undata, Celastraceae, Antibacterial, Antifungal, Cytotoxicity, Haemagglutination assay

\footnotetext{
* Correspondence: lyndy.mcgaw@up.ac.za

'Department of Paraclinical Sciences, Phytomedicine Programme, Faculty of Veterinary Science, University of Pretoria, Private Bag X04, Onderstepoort 0110, South Africa

Full list of author information is available at the end of the article
} 


\section{Background}

The world is currently experiencing challenges of increased resistance development against available antimicrobials. The AIDS pandemic has also resulted in large numbers of immunocompromised patients susceptible to opportunistic bacterial and fungal infections. Toxicity of currently used antimicrobial drugs, such as amphotericin B which causes hepatotoxicity, is a limiting factor in their use. Additionally, the cost of effective antimicrobials plays a vital role in their availability, mainly in developing countries.

The family Celastraceae includes 98 genera with approximately 1264 species [1], and has a long history of use in traditional medicine [2]. These plants are widespread in tropical and subtropical regions including North Africa, South America and East Asia, particularly in China [3]. Maytenus species are either trees or shrubs growing to a height of 1 to $9 \mathrm{~m}$ [4]. They are widely used in folk medicine as anti-tumour, anti-asthmatic and anti-ulcer agents, and as treatments for stomach problems, as analgesics, anti-inflammatories and antimicrobials [5-8].

Maytenus undata (Thunb.) Blakelock, commonly known as kokoboom in Afrikaans, and koko-tree or South African holly, is a shrub or tree about 1.5 to $10 \mathrm{~m}$ high, and is widespread in tropical southern Africa and in south and south-western Arabia [9]. This plant is also called idohame, egqwabali, ikhukhuze, indabulovalo, or inqayi-elibomvu in Zulu [10] and occurs in forests, at forest margins, in ravine forest among boulders and also in open woodland and bushveld, often on termite mounds. Muhammad et al. [7] investigated the chemical constituents of this plant species and isolated 12-oleanene and 3, 4-seco-12-oleanene triterpene acids that had antibacterial activity against Staphylococcus aureus, methicillin-resistant Staphylococcus aureus and Pseudomonas aeruginosa, with MIC values ranging from 3.25 to $50 \mu \mathrm{g} / \mathrm{ml}$. In a preliminary screening study, Maytenus undata extracts had promising antifungal activity against Cryptococcus neoformans, with average minimum inhibitory concentration (MIC) values of 0.09 $\mathrm{mg} / \mathrm{ml}$ after $24 \mathrm{~h}$ incubation [11], leading to a recommendation for further studies on the antifungal activity of $M$. undata. Owing to these results and the use of the species for antimicrobial purposes, the objective of the present study was to isolate antifungal compounds from $M$. undata, and to evaluate their antimicrobial activity and cytotoxicity. Specifically the bioassay-guided fractionation technique was employed to isolate the compounds, using Cryptococcus neoformans as the test organism against which activity was determined using bioautography and a broth microdilution assay. The purified compounds were then tested for efficacy against several other bacterial and fungal species, and for cytotoxicity against Vero African green monkey kidney cells and against equine red blood cells in a haemagglutination assay. Other compounds inactive against $C$. neoformans present in a high concentration were also isolated in the process of fractionation of the M. undata extract, and these were identified and also tested for activity against the suite of bacteria and fungi.

\section{Methods}

\section{Plant collection and extraction}

The leaves of Maytenus undata were collected from the Lowveld National Botanical Gardens, Nelspruit, South Africa in November 2005, just prior to conduction of the study. The identity of the plant material was confirmed by Prof JN Eloff. A voucher specimen was deposited at the HGWJ Schweickerdt Herbarium (University of Pretoria) under the number PRU 115680. The dried $M$. undata leaves $(600 \mathrm{~g})$ were ground to a fine powder and sequentially extracted $(6000 \mathrm{ml} \times 3)$ at room temperature overnight with hexane, dichloromethane, acetone and methanol, successively. The extracts were concentrated under reduced pressure yielding 4.09\% (24.55 g), $2.54 \%$ (15.23 g), $0.75 \%$ (4.47 g) and 13.69\% $(82.16 \mathrm{~g})(\mathrm{w} / \mathrm{w})$, respectively. All the extracts were subjected to bioautography and serial microdilution assays to determine MIC values against Cryptoccocus neoformans.

\section{Bioassay-guided fractionation and isolation}

The hexane fraction $(22.0 \mathrm{~g})$ was chromatographed on silica gel 60 (400 g; $37 \mathrm{~cm} \times 5 \mathrm{~cm}$ column). The column was initially eluted with dichloromethane (DCM, 200 $\mathrm{ml}$ ), and then eluted with ethyl acetate:dichloromethane (EtOAc: DCM) mixtures of increasing polarity (EtOAc: DCM 1:9, 1:4, 3:7, 1:1, 4:1 and 1:0). The polarity of the eluting solvent was sequentially increased to $\mathrm{MeOH}$ : EtOAc (1:9, 1:4, 3:7, 1:1, 4:1 and 1:0). Thirteen fractions of $200 \mathrm{ml}$ were collected, concentrated and analyzed by thin layer chromatography (TLC). Fractions containing similar constituents were combined. Fraction FH1 (2.1 g) obtained from elution with $100 \%$ DCM, was subjected to silica gel $60(65.0 \mathrm{~g})$ column chromatography $(27 \mathrm{~cm} \times 3$ $\mathrm{cm}$ column). The column was eluted with a mixture of hexane:chloroform $\left(\mathrm{CHCl}_{3}\right)$ (1:1) to yield compound 1 . Fraction FH2 (4.5 g), obtained from elution with a mixture of EtOAc: DCM (1:9), was also chromatographed on silica gel 60 (160.0 g; $27.0 \mathrm{~cm} \times 4.5 \mathrm{~cm}$ column) using EtOAc: hexane (1:9) to yield compounds 2 and 3. Fraction FHB $(5.48 \mathrm{~g})$ made up of the combination of fractions FH5 (EtOAc: DCM; 1:1), FH6 (EtOAc: DCM; 4:1) and FH7 (EtOAc: DCM; 1:0) was also separated by repeated silica gel 60 chromatography. Compound 4 was obtained by eluting the silica gel 60 column with a mixture of EtOAc: hexane (1:1) and compound 5 was obtained by eluting the column with $\mathrm{MeOH}: \mathrm{CHCl}_{3}$ (5:95). Fraction FH8 (1.7 g) obtained from elution with a mixture of $\mathrm{MeOH}$ : EtOAc 
(1:9), was also repeatedly subjected to silica gel 60 column chromatography (50 g; $100 \mathrm{~cm} \times 1 \mathrm{~cm}$ column) using $\mathrm{MeOH}: \mathrm{CHCl}_{3}$ (95:5) to yield compound 6 .

\section{TLC fingerprinting}

To facilitate dereplication, or the identification of known compounds in subsequent work, aliquots $(10 \mu \mathrm{l})$ of 1 $\mathrm{mg} / \mathrm{ml}$ solutions in chloroform $\left(\mathrm{CHCl}_{3}\right)$ (equivalent to $10 \mu \mathrm{g}$ ) of each isolated compound were loaded on each of three aluminium-backed thin layer chromatography (TLC) plates (Silica gel $60 \mathrm{~F}_{254}$, Merck) and eluted in three mobile systems of differing polarity [12]. The TLC systems used were as follows:

Benzene:ethanol:ammonium hydroxide (18:2:0.2) (BEA, non-polar)

Chloroform:ethyl acetate:formic acid (10:9:2) (CEF, intermediate polarity)

Ethyl acetate:methanol:water (EMW, 10:1.35:1) (polar)

The developed TLC plates were visualized under UV light at 254 and $365 \mathrm{~nm}$ to detect UV active or absorbing plant constituents. The plates were then sprayed with vanillin spray reagent constituting $0.1 \mathrm{~g}$ vanillin dissolved in $28 \mathrm{ml}$ methanol, with the addition of $1 \mathrm{ml}$ sulphuric acid [13] and heated at $110^{\circ} \mathrm{C}$ to optimal colour development.

\section{Bacterial and fungal cultures}

The test bacteria comprised two Gram-positive species (Staphylococcus aureus, ATCC 29213 and Enterococcus faecalis, ATCC 29212) and two Gram-negative species (Escherichia coli, ATCC 25922 and Pseudomonas aeruginosa, ATCC 27853). The test fungi comprised Candida albicans and Cryptococcus neoformans, clinical isolates from the collection of the Department of Veterinary Tropical Diseases, University of Pretoria. Bacteria were maintained on Müller-Hinton $(\mathrm{MH})$ agar at $4^{\circ} \mathrm{C}$ and were cultured in $\mathrm{MH}$ broth at $37^{\circ} \mathrm{C}$. Fungi were maintained on Sabouraud Dextrose (SD) agar at $4^{\circ} \mathrm{C}$ and were inoculated in SD broth at $35^{\circ} \mathrm{C}$ and incubated overnight prior to conducting bioautography and microdilution assays.

\section{Bioautographic assays}

Aliquots $(10 \mu \mathrm{g})$ of each isolated compound were loaded on five aluminium-backed thin layer chromatography (TLC) plates (Merck, silica gel $60 \mathrm{~F}_{254}$ ) and were prepared in the solvent systems mentioned above. The plates were left uncovered in a dark place for several days to allow the eluting solvent to evaporate completely from the plates before being sprayed with a day-old actively growing suspension of bacterial and fungal cultures. The TLC plates were then incubated for 24 hours at $37^{\circ} \mathrm{C}$ under $100 \%$ relative humidity to allow the microorganism to grow on the plates. After overnight incubation the bioautograms were sprayed with $2 \mathrm{mg} / \mathrm{ml}$ $p$-iodonitrotetrazolium violet (INT, Sigma) in water and incubated for 30 minutes for the development of clear zones against a red background indicating inhibition of fungal growth by isolated bioactive compounds $[14,15]$.

\section{Microdilution assay}

The two-fold serial dilution microplate method [16] was used to determine the MIC values of plant extracts. This method has been used to evaluate antibacterial activities of plant extracts $[16,17]$. The method has been modified for evaluating antifungal activity [18]. Briefly, aliquots (100 $\mu \mathrm{l})$ of $1 \mathrm{mg} / \mathrm{ml}$ solutions dissolved in acetone of the isolated compounds were serially diluted with distilled water in 96well microtitre plates. A $100 \mu \mathrm{l}$ aliquot of bacterial and fungal suspension was added to each well. Acetone was used as a solvent control and distilled water was used as a negative control because it is the least toxic to fungi of watermiscible extractants that would dissolve more non-polar compounds [19]. Amphotericin B and gentamicin were used as positive controls against fungi and bacteria respectively. For the antifungal assay, $40 \mu \mathrm{l}$ of $0.2 \mathrm{mg} / \mathrm{ml}$ of INT was added to each well and the covered and sealed microtitre plates were incubated at $35^{\circ} \mathrm{C}$ overnight to ensure adequate colour development. For the antibacterial assay, INT was added after overnight incubation of the plant extracts with bacterial cultures at $37^{\circ} \mathrm{C}$ and incubated for a further $30 \mathrm{~min}$ to 1 hour until optimal colour development. The colourless tetrazolium salt acts as an electron acceptor and is reduced to a formazan product by biologically active organisms. Tests were carried out in triplicate and each experiment was repeated three times. The MIC was recorded as the lowest concentration of the extract that inhibited fungal or bacterial growth [16].

\section{Cytotoxicity}

\section{Tetrazolium-based colorimetric assay (MTT)}

The MTT assay procedure [20] with slight modifications [21] was used to investigate cytotoxicity of the four isolated compounds 1, 3, 5 and 6 that were available in sufficient quantity to perform the test. Isolated compounds were tested for cytotoxicity against Vero monkey kidney cells obtained from the Department of Veterinary Tropical Diseases (University of Pretoria). The cells were maintained in minimal essential medium (MEM, Highveld Biological, Johannesburg, South Africa) supplemented with 0.1\% gentamicin (Virbac) and 5\% foetal calf serum (AdcockIngram). Cell suspensions were prepared from confluent monolayer cultures and plated at a density of $2 \times 10^{3}$ cells into each well of a 96-well microtitre plate. Plates were incubated overnight at $37^{\circ} \mathrm{C}$ in a $5 \% \mathrm{CO}_{2}$ incubator to allow 
attachment of cells prior to use in the cytotoxicity assay. Stock solutions of the isolated compounds $(20 \mathrm{mg} / \mathrm{ml})$ were prepared by dissolving them in DMSO. Appropriate dilutions of the isolated compounds were prepared in growth medium and added to the cells.

The viable cell growth after incubation for 120 hours with isolated compounds was determined using the 3-(4,5-dimethylthiazol)-2,5-diphenyl tetrazolium bromide (MTT) assay, a tetrazolium-based colorimetric assay [20]. After incubation, a washing step was included to remove traces of the test compounds, as it has been demonstrated that some botanical extracts or components can reduce MTT in the absence of living cells [22]. The supernatant was aspirated from the cells and $200 \mu \mathrm{l}$ of phosphate buffered solution (PBS) used to rinse each well. The PBS was in turn aspirated and replaced with $200 \mu \mathrm{l}$ of fresh growth medium. Following the washing step, $30 \mu \mathrm{l}$ of MTT (5 $\mathrm{mg} / \mathrm{ml}$ in PBS) was added to each well and the plates were incubated for a further 4 hours. The medium was aspirated from the wells and $50 \mu \mathrm{LMSO}$ added to each well to solubilize the formazan produced by mitochondrial activity. The absorbance was measured on a Versamax microplate reader (Molecular Devices) at $570 \mathrm{~nm}$. Berberine chloride (Sigma) was used as a positive control and appropriate negative controls were included. The intensity of colour is directly proportional to the number of surviving cells. Tests were carried out in quadruplicate and each experiment was repeated three times. Selectivity index values were calculated by dividing cytotoxicity $\mathrm{LC}_{50}$ values by the $\mathrm{MIC}$ values $\left(\mathrm{SI}=\mathrm{LC}_{50} / \mathrm{MIC}\right)$.

\section{Haemagglutination assay (HA)}

The haemagglutination assay was used to determine toxicity of the isolated compounds to erythrocyte membranes. The degree of toxicity is indicated by agglutination of the RBCs due to the change in the physiology of the blood cell membrane [23]. Equine erythrocytes fixed with formalin were prepared according to the technique of Sadique et al. [24]. Fresh blood was collected from a horse (Equine Research Centre, Faculty of Veterinary Sciences, University of Pretoria) into clean, dry glass tubes containing 3.8\% sodium citrate (9 parts blood: 1 part $3.8 \%$ sodium citrate). The blood was centrifuged at $4000 \mathrm{rpm}$ for $10 \mathrm{~min}$. The packed RBCs were washed with $10 \mathrm{mM}$ phosphatebuffered saline (PBS), $\mathrm{pH}$ 7.2, until a clear supernatant was obtained. The washed and packed RBCs were suspended in $5 \%(\mathrm{v} / \mathrm{v})$ formaldehyde in PBS $(1: 12.3 \mathrm{v}: \mathrm{v})$. The mixture was left at room temperature for 24 hours. The final fixed RBC were washed and centrifuged with PBS three times [23].

The haemagglutination assay was then conducted [23,24]. PBS $(100 \mu \mathrm{l})$ was placed into U-shaped 96-well microtitre plates. The first row was used as a control without extracts. Isolated compounds 1, 3, 5 and $6(100 \mu \mathrm{l}$ of $3 \mathrm{mg} / \mathrm{ml}$ solution in acetone) were added to the second row and were serially diluted two-fold down the column. Then, $50 \mu \mathrm{l}$ of horse RBCs were added to all the wells and incubated at room temperature for 1 hour. The presence of buttons in the centre of the well indicated no agglutination i.e. RBC membranes are not disrupted, hence no toxicity of the extract or isolated compounds. Acetylsalicyclic acid was used as a positive control. The haemagglutination (HA) titre value of the extracts was calculated as the reciprocal of the last dilution concentration showing agglutination, and was calculated using the formula HA titre value $=1$ /concentration value. A high $\mathrm{HA}$ titre value indicates a high level of toxicity which could cause serious toxic effects, particularly on the RBC blood group [23]. The samples were tested in triplicate in each assay and experiments were repeated three times.

\section{Results and discussion Bioactivity of extracts}

The hexane fraction $(\mathrm{MIC}=0.02 \mathrm{mg} / \mathrm{ml}$ ) had a higher antifungal activity against $C$. neoformans than the other fractions, namely DCM $(\mathrm{MIC}=0.04 \mathrm{mg} / \mathrm{ml})$, acetone $(\mathrm{MIC}=0.08 \mathrm{mg} / \mathrm{ml})$ and $\mathrm{MeOH}(\mathrm{MIC}=0.56 \mathrm{mg} / \mathrm{ml})$. It is clear that there was a good correlation between nonpolarity and antifungal activity as the more non-polar the solvent used to prepare the fraction, the higher the activity. The hexane extract yielded a clear broad band on bioautograms against $C$. neoformans (results not shown). This implies that several active compounds that were not well separated were present. Hence, isolation of the active compounds was continued using the hexane extract.

\section{Chemical structures of the isolated compounds}

The structures of the isolated compounds 1-6 were determined by ${ }^{1} \mathrm{H}$ and ${ }^{13} \mathrm{C}$ NMR spectroscopy and by comparison of the spectral data with published data. The isolated compounds were identified as friedelin (1) (175 mg; $0.029 \%, \mathrm{w} / \mathrm{w}$ of hexane fraction) [25], friedelan$3 \beta$-ol (2) (15 mg; 0.0025\%, w/w) [26], taraxerol (3) (155 $\mathrm{mg} ; 0.026 \%, \mathrm{w} / \mathrm{w})$ [27], 3-oxo-11 $\alpha$-methoxyolean-12-ene30-oic acid (4) (23 mg; 0.0038\%, w/w) [7], 3-oxo-11 $\alpha$ hydroxyolean-12-ene-30-oic acid (5) (82 mg; 0.014\%, w/w) [7] and 3,11-dihydroxyolean-12-ene-30-oic acid (6) (68 $\mathrm{mg} ; 0.011 \%, \mathrm{w} / \mathrm{w})$. Compound 6 is closely related to glycyrrhetinic acid which is produced by the hydrolysis of glycyrrhizinic acid, a major component of Glycyrrhiza glabra [28]. Glycyrrhetinic acid has a keto group at C11, while compound 6 has a hydroxyl group. This is the first report to our knowledge of the isolation and structure of compound 6 from a plant species. The structures of the isolated compounds are shown in Figure 1. 


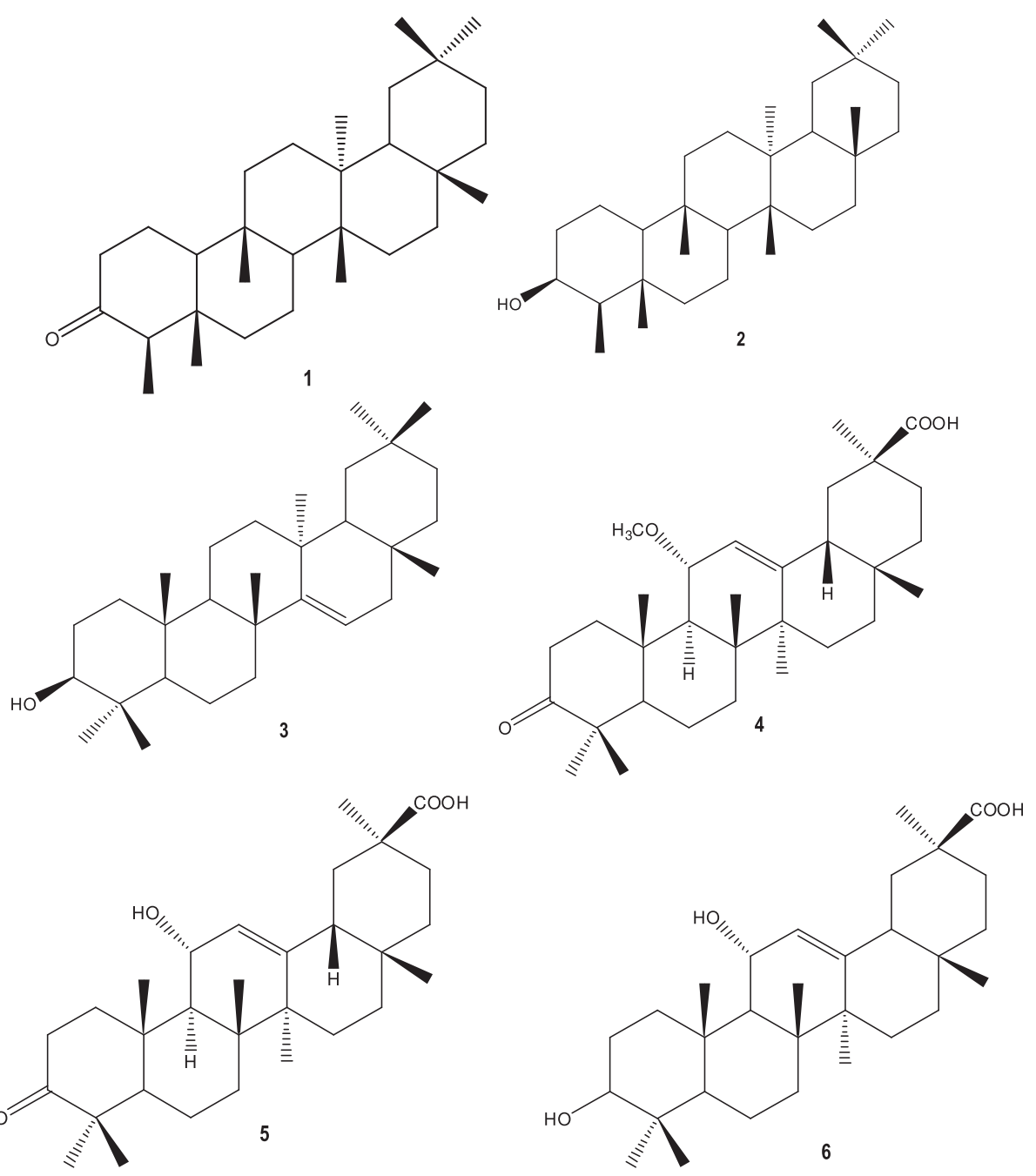

Figure 1 Structures of compounds isolated from Maytenus undata leaves: friedelin (1), friedelan-3 $\beta$-ol (2), taraxerol (3), 3-oxo-11amethoxyolean-12-ene-30-oic acid (4), 3-oxo-11a-hydroxyolean-12-ene-30-oic acid (5), 3,11-dihydroxyolean-12-ene-30-oic acid (6).

As an aid to dereplication, which prevents isolation of the same antifungal compounds from other plant species in future, the retention factor $\left(\mathrm{R}_{\mathrm{f}}\right)$ values for active compounds in three TLC solvent systems were determined. The $R_{f}$ values of the isolated compounds ranged from 0.95 to 0.03 in BEA, 0.95 to 0.78 in CEF and 0.93 to 0.83 in EMW (Table 1).

\section{Bioautographic assays of the isolated compounds}

Friedelin (1) did not produce any bands of inhibition against any of the tested microorganisms, meaning that no tested microorganisms were susceptible to the $10 \mu \mathrm{g}$ of friedelin loaded on the TLC plate. Another explanation is that this non-polar compound may be so volatile that it may have evaporated from the chromatogram while the eluent was removed. Taraxerol (3) did produce clear bands against both $C$. neoformans and $E$. coli; however there were no clear growth inhibitory bands on the bioautograms sprayed with $P$. aeruginosa and $S$. aureus. All the microorganisms were sensitive to 3-oxo$11 \alpha$-hydroxyolean-12-ene-30-oic acid (5) and 3,11dihydroxyolean-12-ene-30-oic acid (6). Friedelan-3 $\beta$-ol (2) and 3-oxo-11 $\alpha$-methoxyolean-12-ene-30-oic acid (4)

Table 1 Retention factor $\left(R_{f}\right)$ values of the isolated compounds in different mobile systems: friedelin (1), friedelan-3 $\beta$-ol (2), taraxerol (3), 3-oxo-11a-methoxyolean12-ene-30-oic acid (4), 3-oxo-11a-hydroxyolean-12-ene-30oic acid (5), 3,11-dihydroxyolean-12-ene-30-oic acid (6)

\begin{tabular}{lllllll}
\hline Mobile phase & \multicolumn{6}{l}{$\mathbf{R}_{\mathbf{f}}$ values of the isolated compounds } \\
\cline { 2 - 7 } & $\mathbf{1}$ & $\mathbf{2}$ & $\mathbf{3}$ & $\mathbf{4}$ & $\mathbf{5}$ & $\mathbf{6}$ \\
\hline BEA & 0.95 & 0.85 & 0.73 & 0.14 & 0.04 & 0.03 \\
CEF & 0.95 & & 0.91 & & 0.77 & 0.78 \\
EMW & 0.93 & & 0.92 & & 0.87 & 0.83 \\
\hline
\end{tabular}


were not isolated in sufficient quantities for bioautographic analysis.

\section{Minimum inhibitory concentrations}

No microorganism was susceptible to friedelin (1) at the highest concentration tested $(250 \mu \mathrm{g} / \mathrm{ml})$ indicating that the lack of active bands in bioautography was not caused by the evaporation of friedelin. Only E. faecalis $(\mathrm{MIC}=130 \pm 0.04 \mu \mathrm{g} / \mathrm{ml})$ had some sensitivity to taraxerol (3). Both fungal species tested were sensitive to 3-oxo-11 $\alpha$-hydroxyolean-12-ene-30-oic acid (5) and 3,11-dihydroxyolean-12-ene-30-oic acid (6). However, 3-oxo-11 $\alpha$-hydroxyolean-12-ene-30-oic acid (5) was slightly more active against Cryptococcus neoformans $(47 \pm 0.01 \mu \mathrm{g} /$ $\mathrm{ml})$ than Candida albicans $(63 \pm 0.02 \mu \mathrm{g} / \mathrm{ml})$ (Table 2). In general there was a good correlation between the bioautography and serial microdilution results.

A review of the available literature indicates that not one of the isolated compounds has been tested for antifungal activity against $C$. neoformans, but some of the compounds have been tested against $C$. albicans and some bacterial species. Friedelin (1) has antifungal activity against $C$. albicans with an MIC value of $2.44 \mu \mathrm{g} / \mathrm{ml}$ [29]. Our results could not confirm the antifungal activity of this compound against C. albicans. In addition, the antibacterial activity of friedelin (1) against $E$. faecalis with an MIC value of $0.61 \mu \mathrm{g} / \mathrm{ml}$ was reported [29]. No antibacterial activity against $P$. aeruginosa and $S$. aureus was detected [29], in agreement with our results.

Staphylococcus aureus was least sensitive to all the tested compounds, with MIC values greater than $250 \mu \mathrm{g} / \mathrm{ml}$, the highest concentration tested. All the other pathogens were sensitive to 3-oxo-11 $\alpha$-hydroxyolean-12-ene-30-oic acid (5) with MIC values of $36 \pm 0.04 \mu \mathrm{g} / \mathrm{ml}$ and $32 \pm 0.02 \mu \mathrm{g} / \mathrm{ml}$ for $P$. aeruginosa and $E$. coli respectively. Muhammad and colleagues [7] showed that compound 5 was active against
$S$. aureus and $P$. aeruginosa with $\mathrm{MIC}$ values $>10 \mu \mathrm{g} / \mathrm{ml}$ and $6.25 \mu \mathrm{g} / \mathrm{ml}$, respectively.

Compound 6 (11-dihydroxyolean-12-ene-30-oic acid) has a similar structure to glycyrrhetinic acid and it was more active against $E$. coli $(\mathrm{MIC}=24 \pm 0.05 \mu \mathrm{g} / \mathrm{ml})$ than any of the other microorganisms tested. Glycyrrhetinic acid did not inhibit the growth of E. coli (KCTC 1682) and C. albicans (KCTC 7270) [30], but compound 6 had substantial activity against most of the tested microorganisms in this study with MIC values ranging from 24 to $63 \mu \mathrm{g} / \mathrm{ml}$, except against S. aureus which was less susceptible. The reason for this difference in activity might be due to the presence of two hydroxyl groups in compound 6, compared to glycyrrhetinic acid which contains a keto group and lacks a hydroxyl group.

Compounds 1 and 3 were not highly active against the tested microorganisms, especially against $C$. neoformans. Amphotericin B had an MIC value of $0.16 \pm 0.00 \mu \mathrm{g} / \mathrm{ml}$ but both compounds 5 and 6 had MIC values of $47 \mu \mathrm{g} / \mathrm{ml}$ against $C$. neoformans. The crude hexane extract had an MIC of $20 \pm 0.00 \mu \mathrm{g} / \mathrm{ml}$ against $C$. neoformans, and was therefore more active than compounds 5 and 6 . In addition, hexane crude extract bioautograms against $C$. neoformans displayed a broad clear zone of fungal growth inhibition, indicating the presence of antifungal constituents with very similar retention indices. Hence, the separation of activity into single pure components was not achieved, resulting in a reduced antifungal activity. This suggests the possibility of synergistic effects between active or even non-active plant constituents in the M. undata extract which might influence the uptake of active constituents by microorganisms. This phenomenon is possible in plant extracts containing numerous constituents responsible for different properties within the plant. Some of the compounds which showed activity on bioautograms were not isolated in this study because they were

Table 2 MIC values and cytotoxicity of the hexane crude extract and isolated compounds from M. undata

\begin{tabular}{|c|c|c|c|c|c|c|c|c|}
\hline & \multicolumn{6}{|c|}{ Minimum inhibitory concentration (MIC, $\mu \mathrm{g} / \mathrm{ml})$} & \multicolumn{2}{|l|}{ Cytotoxicity } \\
\hline & C. albicans & C. neoformans & E. coli & E. faecalis & S. aureus & P. aeruginosa & $\begin{array}{l}\text { Vero cells }\left(L C_{50}\right) \\
(\mu \mathrm{g} / \mathrm{ml})\end{array}$ & HA titre value \\
\hline Hexane extract & $300 \pm 0.01$ & $20 \pm 0.00$ & $120 \pm 0.06$ & $80 \pm 0.03$ & $630 \pm 0.00$ & $300 \pm 0.00$ & $76 \pm 0.05$ & 1.60 \\
\hline Compound $1^{1}$ & $>250 \pm 0.00$ & $>250 \pm 0.00$ & $>250 \pm 0.00$ & $>250 \pm 0.00$ & $>250 \pm 0.00$ & $>250 \pm 0.00$ & $>200 \pm 0.00$ & $* * 2$ \\
\hline Compound 3 & $>250 \pm 0.00$ & $>250 \pm 0.00$ & $>250 \pm 0.00$ & $130 \pm 0.04$ & $>250 \pm 0.00$ & $>250 \pm 0.01$ & $>200 \pm 0.00$ & $* * 2$ \\
\hline Compound 5 & $63 \pm 0.02$ & $47 \pm 0.01$ & $32 \pm 0.02$ & $32 \pm 0.05$ & $>250 \pm 0.01$ & $36 \pm 0.04$ & $6.03 \pm 0.02$ & 1.33 \\
\hline Compound 6 & $63 \pm 0.05$ & $47 \pm 0.02$ & $24 \pm 0.05$ & $63 \pm 0.04$ & $>250 \pm 0.00$ & $32 \pm 0.02$ & $2.98 \pm 0.01$ & 0.67 \\
\hline Amphotericin B & $0.16 \pm 0.00$ & $0.16 \pm 0.00$ & & & & & & \\
\hline Gentamicin & & & $6.30 \pm 0.00$ & $25 \pm 0.00$ & $15 \pm 0.01$ & $3.20 \pm 0.03$ & & \\
\hline Berberine & & & & & & & $12.35 \pm 0.00$ & \\
\hline Acetylsalicyclic acid & & & & & & & & 0.80 \\
\hline
\end{tabular}

${ }^{1}$ friedelin (1), friedelan-3ß-ol (2), taraxerol (3), 3-oxo-11a-methoxyolean-12-ene-30-oic acid (4), 3-oxo-11a-hydroxyolean-12-ene-30-oic acid (5), 3,11-dihydroxyolean12-ene-30-oic acid (6).

2** Low haemagglutination (HA) titre value (compounds not toxic). 
present in quantities too low to isolate using these methods. These compounds may contribute to synergistic effects, resulting in total activity of the crude extract.

\section{Cytotoxicity \\ MTT assay}

Both friedelin (1) and taraxerol (3) were slightly toxic to the Vero cells with an $\mathrm{LC}_{50}$ higher than the highest concentration $(200 \mu \mathrm{g} / \mathrm{ml})$ tested. The compounds 3-oxo-11 $\alpha$-hydroxyolean-12-ene-30-oic acid (5) and 3,11dihydroxyolean-12-ene-30-oic acid (6) were relatively toxic with $\mathrm{LC}_{50}$ values of $6.03 \pm 0.02$ and $2.98 \pm 0.01 \mu \mathrm{g} / \mathrm{ml}$, respectively. Berberine had an $\mathrm{LC}_{50}$ of $12.4 \pm 0.00 \mu \mathrm{g} / \mathrm{ml}$, calculated from the regression curve. Upon calculating the therapeutic index of compounds 5 and 6 against five of the pathogens by dividing the $\mathrm{LC}_{50}$ by the MIC, values between 0.05 and 0.12 were obtained, indicating that the compounds are much more toxic to the Vero cells than to the pathogens. Selectivity index (SI) values calculated using the cytotoxicity results against Vero cells and MIC values (Table 3 ) showed that the crude hexane extract had the best SI value of 3.80 against C. neoformans, but none of the compounds had SI values above 1, indicating that bioactivity was most likely owing to general toxic effects of the plant constituents isolated. It is possible that structure-activity studies and chemical modification experiments could reduce toxicity and enhance activity of the isolated compounds to increase their potential usefulness in future.

\section{Haemagglutination assay}

As with the Vero cell assay friedelin (1) and taraxerol (3) were not toxic to the formaldehyde-fixed red blood cells even at the highest concentration tested $(3000 \mu \mathrm{g} / \mathrm{ml})$. However, compounds 5 and 6 caused agglutination of the RBCs. These compounds were toxic with high HA titre values of 1.33 and 0.67 respectively to the formaldehydefixed RBCs, so compound 5 was more toxic to the RBCs than compound 6. The positive control, acetylsalicyclic acid, showed less toxicity than compound 5 and no significant difference was observed when compared with compound 6.

\section{Chemical structures and activity}

The structures of the isolated compounds 3-oxo-11 $\alpha$ methoxyolean-12-ene-30-oic acid (4), 3-oxo-11 $\alpha$-hydroxyolean-12-ene-30-oic acid (5) and 3,11-dihydroxyolean12-ene-30-oic acid (6) belong to the 12-oleanene group, just like oleanolic acid and its derivatives such as ursolic acid and betulinic acid with known antifungal and antibacterial activity [31,32]. From the current literature it is evident that a simple structural modification of a parent compound can dramatically influence biological activity $[33,34]$. The biological activity can either increase or decrease depending on the modification that has occurred. Compounds with additional oxygen function(s) to those in oleanolic acid and pomolic acid showed decreased antiHIV activity [33,34]. This means that active compounds with fewer polar oxygen substituents may inhibit microbial growth because of the high hydrophobic interaction with target microbial cells. The compounds 3-oxo-11 $\alpha$ hydroxyolean-12-ene-30-oic acid (5) and 3,11-dihydroxyolean-12-ene-30-oic acid (6) isolated in this study can potentially act as lead compounds in the development of more potent antimicrobials against bacterial and fungal infections.

\section{Conclusions}

This study investigated the potential significance of Maytenus undata extracts and isolated compounds in the development of new antibacterial and antifungal drugs, following the widespread use of Maytenus species in traditional medicine for antimicrobial purposes. In vitro antimicrobial activity evaluation of pure compounds from crude plant extracts can play a major role in the discovery of potential new drug leads. The simultaneous biological activity and cytotoxicity evaluation of isolated pure compounds and plant extracts provides valuable information regarding the prospective use of medicinal plants as sources of new drugs. Also, it emphasizes the rationale for using medicinal plants in folk

Table 3 Selectivity index values of the hexane crude extract and isolated compounds from $M$. undata

\begin{tabular}{|c|c|c|c|c|c|c|}
\hline & \multicolumn{6}{|c|}{ Selectivity index values ( $\left.\mathrm{LC}_{50} / \mathrm{MIC}\right)$} \\
\hline & C. albicans & C. neoformans & E. coli & E. faecalis & S. aureus & P. aeruginosa \\
\hline Hexane extract & 0.25 & 3.80 & 0.63 & 0.95 & 0.12 & 0.25 \\
\hline Compound $1^{1}$ & $N C^{2}$ & NC & NC & NC & NC & NC \\
\hline Compound 3 & $\mathrm{NC}$ & NC & NC & $\mathrm{NC}$ & NC & NC \\
\hline Compound 5 & 0.096 & 0.13 & 0.19 & 0.19 & NC & 0.17 \\
\hline Compound 6 & 0.047 & 0.063 & 0.12 & 0.047 & NC & 0.093 \\
\hline
\end{tabular}

${ }^{1}$ friedelin (1), friedelan-3ß-ol (2), taraxerol (3), 3-oxo-11a-methoxyolean-12-ene-30-oic acid (4), 3-oxo-11a-hydroxyolean-12-ene-30-oic acid (5), 
medicine. The antibacterial and antifungal activity of $M$. undata extracts and isolated compounds may validate the traditional use of the plant as an antimicrobial agent and as a treatment for stomach problems.

With many people relying on plant products for their primary health care needs, possible toxicity to humans is a worrying factor. Therefore, it is useful to highlight where general toxicity is not responsible for the observed biological activity. In this study, the most active isolated compounds, 3-oxo-11 $\alpha$-hydroxyolean-12-ene-30-oic acid (5) and 3,11-dihydroxyolean-12-ene-30-oic acid (6) were relatively cytotoxic to monkey kidney cells. Structural modifications of active compounds may play a crucial role in advancing their development into useful drugs with reduced toxicity. The discovery of active compounds against opportunistic infections like C. albicans, C. neoformans and $S$. aureus will add significant value in the treatment of various human ailments such as HIV-AIDS with its associated opportunistic pathogens and sexually transmitted infections (STIs). Therefore, more directed research is needed to explore the ability of plants to enhance the discovery and development of new chemical entities.

\section{Abbreviations}

DCM: Dichloromethane; EtOAc: Ethyl acetate; HA: Haemagglutination assay; INT: $p$-iodonitrotetrazolium violet; $\mathrm{MeOH}$ : Methanol; $\mathrm{MH}$ : Müller-Hinton; MIC: Minimum inhibitory concentration; MTT: 3-(4,5-dimethylthiazol-2-yl)-2, 5-diphenyltetrazolium bromide; RBCs: Red blood cells; SD: Sabouraud Dextrose; TLC: Thin Layer Chromatography.

\section{Competing interests}

The authors declare that they have no competing interests.

\section{Authors' contributions}

TAM conducted all the practical work and drafted the manuscript, LJM co-supervised the research design and implementation, was instrumental in performing the cytotoxicity study and edited the manuscript, LKM assisted with the isolation and structure elucidation of the compounds, VPB assisted with various aspects of the practical work, EOI helped with the haemagglutination study and JNE supervised the design of the research and helped edit the manuscript. All authors read and approved the final manuscript.

\section{Acknowledgements}

The curator of the Lowveld National Botanical Garden allowed us to collect plant material and the Medical Research Council of South Africa provided funding.

\footnotetext{
Author details

${ }^{1}$ Department of Paraclinical Sciences, Phytomedicine Programme, Faculty of Veterinary Science, University of Pretoria, Private Bag X04, Onderstepoort 0110, South Africa. ${ }^{2}$ Present address: Department of Health, Medicines Evaluations and Research, Private Bag X828, Pretoria 0001, South Africa. ${ }^{3}$ Present address: Department of Pharmacy, University of Limpopo, Private Bag X1106, Sovenga 0727, South Africa. ${ }^{4}$ Present address: Department of Biochemistry, Microbiology and Biotechnology, University of Limpopo, Private Bag X1106, Sovenga 0727, South Africa. ${ }^{5}$ Present address: Department of Pharmacology, Faculty of Pharmacy, Obafemi Awolowo University, Ile-Ife, Nigeria.
}

Received: 20 December 2012 Accepted: 14 May 2013

Published: 20 May 2013

\section{References}

1. Simmons MP, Savolainen V, Clevinger CC, Archer RH, Davis Jl: Phylogeny of the Celastraceae inferred from 26S Nuclear Ribosomal DNA, Phytochrome B, rbcL, atpB, and morphology. Mol Phylogenet Evol 2001, 19:353-366.

2. Gonazález AG, Bazzocchi IL, Moujir LM, Jiménez IA, In: Studies in Natural Chemistry, Bioactive Natural Products (Part D): Elsevier Science: Edited by Atta-ur Rahman, Amsterdam; 2000:23-649.

3. Spivey AC, Weston M, Woodhead S: Celastraceae sesquiterpenoids: biological activity and synthesis. Chem Soc Rev 2002, 31:43-59.

4. Robson NKB, Halle N, Mathew N: Blakelock R: Celastraceae. In Flora of Tropical East Africa. Edited by. Polhill RM, Rotterdam: Balkema; 1994.

5. Orabi KY, Al-Qasoumi SI, El-Olemy MM, Mossa JS, Muhammad I: Dihydroagarfuran alkaloids and tritepenes from Maytenus arbutifolia. Phytochemistry 2001, 58:475-480.

6. Ghazanfar SA: Handbook of Arabian Medicinal Plants. Boca Raton: CRC Press; 1994:83.

7. Muhammad I, El-Sayed KA, Mossa JS, Al-Said MS, El-Feraly FS, Clark AM, Hufford CD, Mayer AMS: Bioactive 12-oleanene triterpene and secotriterpene acids from Maytenus undata. J Nat Prod 2000, 63:605-610.

8. Al Haidari R: Phytochemical and biological study of Maytenus forsskaoliana (Sebsebe). KSA: MSc Thesis; KSU, Riyadh; 2002.

9. Collenette S: An illustrated guide to the flowers of Saudi Arabia. Scorpion Publishing Ltd, London: Kingdom of Saudi Arabia, Flora, Publication No. 1; 1985:114.

10. Hutchings A, Scott A, Lewis A: Cunningham AB: Zulu Medicinal Plants: An Inventory. Pietermaritzburg: University of Natal Press; 1996.

11. Mokoka TA, McGaw $\sqcup$, Eloff JN: Antifungal efficacy of ten selected South African plant species against Cryptococcus neoformans. Pharm Biol 2010, 48:397-404

12. Kotzé M, Eloff JN: Extraction of antibacterial compounds from Combretum microphyllum (Combretaceae). S Afr J Bot 2002, 68:62-67.

13. Wagner H, Bladt S: Plant Drug Analysis: A Thin Layer Chromatography Atlas. 2nd edition. Berlin: Springer; 1996.

14. Begue WJ: Kline RM: The use of tetrazolium salts in bioautography procedures. J Chromatogr 1972, 88:182-184.

15. Masoko P, Eloff JN: The diversity of antifungal compounds of six South African Terminalia species (Combretaceae) determined by bioautography. Afr J Biotechnol 2005, 4:1425-1431.

16. Eloff JN: A sensitive and quick microplate method to determine the minimum inhibitory concentration of plant extracts for bacteria. Planta Med 1998, 64:711-713.

17. McGaw LJ, Rabe T, Sparg SG, Jäger AK, Jäger AK, van Staden J: An investigation on the biological activity of Combretum species. J Ethnopharmacol 2001, 75:45-50.

18. Masoko P, Picard J: Eloff JN: Antifungal activities of six South African Terminalia species (Combretaceae). J Ethnopharmacol 2005, 99:301-308.

19. Eloff JN, Picard J, Masoko P: Resistance of animal fungal pathogens to solvents used in bioassays. S Afr J Bot 2007, 73:667-669.

20. Mosmann T: Rapid colorimetric assay for cellular growth and survival: application to proliferation and cytotoxicity. J Immunol Methods 1983, 65:55-63.

21. McGaw LJ, Steenkamp V, Eloff JN: Evaluation of Athrixia bush tea for cytotoxicity, antioxidant activity, caffeine content and presence of pyrrolizidine alkaloids. J Ethnopharmacol 2007, 110:16-22.

22. Shoemaker M, Cohen I, Campbell M: Reduction of MTT by aqueous herbal extracts in the absence of cells. J Ethnopharmacol 2004, 93:381-384.

23. Iwalewa EO, Adewunmi CO, Omisore NOA, Adebanji OA, Azike CK, Adigun $A O$, Adesina OA, Olowoyo OG: Pro- and antioxidant effects and cytoprotective potentials of nine edible vegetables in Southwest Nigeria. $J$ Med Foods 2005, 8:539-544

24. Sadique J, Al-Rqobab NA, Bughaith MF, El-Gindy AR: The bioactivity of certain medicinal plants on the stabilization of RBC membrane system. Fitoterapia 1989, 60:525-532.

25. Hisham A, Jaya Kumar G, Fujimoto Y, Hara N: Salacianone and salacianol, two triterpenes from Salacia beddomei. Phytochemistry 1995, 40:1227-1231.

26. Kundu JK, Rouf ASS, Nazmul Hossain M, Hasan CM, Rashid MA: Antitumor activity of epifriedelanol from Vitis trifolia. Fitoterapia 2000, 7:577-579.

27. Sakurai N, Yaguchi Y, Inoue T: Triterpenoids from Myrica rubra. Phytochemistry 1987, 26:217-219.

28. Salari MH, Kadkhoda Z: In vitro antibacterial effects of glycyrrhetinic acid on periodontopathogenic and capnophilic bacteria isolated from adult periodontitis.Clinical Microbiology and. Infection 2003, 9:987-988. 
29. Kuete V, Komguem J, Penlap Beng V, Meli AL, Tangmouo JG, Etoa FX, Lontsi $D$ : Antimicrobial components of the methanolic extract from the stem bark of Garcinia smeathmannii Oliver (Clusiaceae). S Afr J Bot 2007, 73:347-354.

30. Kim HK, Park Y, Kim HN, Choi BH, Jeong HG, Lee DG, Hahm K: Antimicrobial mechanism of $\beta$-glycyrrhetinic acid isolated from licorice. Glycyrrhiza glabra Biotechnol Lett 2002, 24:1899-1902.

31. Liu J: Pharmacology of oleanolic acid and ursolic acid. J Ethnopharmacol 1995, 49:57-68.

32. Fontanay S, Grare M, Mayer J, Finance C, Duval RE: Ursolic, oleanolic and betulinic acids: antibacterial spectra and selectivity indexes. J Ethnopharmacol 2008, 120:272-276.

33. Kashiwada M, Shirakata Y, Inoue J, Nakano H, Okazaki K, Okumura K, Yamamoto T, Nagaoka H, Takemori T: Tumor necrosis factor receptorassociated factor 6 (TRAF6) stimulates extracellular signal-regulated kinase (ERK) activity in CD40 signaling along a ras-independent pathway. J Exp Med 1998, 187:237-244.

34. Zloh M, Bucar F, Gibbons S: Quantum chemical studies on structure activity relationship of natural product polyacetylenes. Theor Chem Acc 2007, 117:247-252.

doi:10.1186/1472-6882-13-111

Cite this article as: Mokoka et al:: Antimicrobial activity and cytotoxicity of triterpenes isolated from leaves of Maytenus undata (Celastraceae). BMC Complementary and Alternative Medicine 2013 13:111.

\section{Submit your next manuscript to BioMed Central and take full advantage of:}

- Convenient online submission

- Thorough peer review

- No space constraints or color figure charges

- Immediate publication on acceptance

- Inclusion in PubMed, CAS, Scopus and Google Scholar

- Research which is freely available for redistribution 